\title{
S46. Community psychiatry in post-socialist countries
}

STATE, PROBLEMS AND NEEDS OF THE MENTAL HEALTH WORK IN ESTONIA.

A. Kasme!

Estonian Centre for Health Promotion, Rüütli tn, 24, EE-0001 Tallinn

The present situation of political and socioeconomic development constitutes a unique occasion for redefining priorities, strategies and policies for health care development. Particular attention needs to be given to the mental and psychological health, needs of vulnerable groups and to the care of mentally ill and disabled as these groups have been stigmatized and neglected in the past.

The Law of Psychiatry is in preparing stage and Mental Health Law is under discussion.

New health polices and legislation should contain a strong mental health component. The need for focus on out-patient and community based services which allow for humane, rehabilitative, integrative and preventive development; include the long-term mentally ill, substance abusers and persons at risk for suicide.

It is agreed to establish a ministerial agency with the authority to plan and carry out mental health care policy, to work out concepts of mental health, define aims, strategy, priorities, to support training and research in mental health, and emphasizing a multidisciplinary approach to develop the social services component in mental health care.
THE PRESENT DAY SITUATION OF LATVIAN PSYCHIATRY A. Apsite

Riga Psychoneurological Centre, Kr. Valdemare st. 33, Riga, Latvia

During the period of russification under the totalitarian regime the same rules existed in Latvia as in the whole Soviet Union. There were special laws and instructions applied in psychiatry. Each client was registered. The human rights of these clients depended not on the concrete clinical psychiatric state, but on the diagnosis. For example, a schizophrenic client was not allowed to drive a car, to go abroad, had some restrictions in receiving education. It resulted in the beginning of antipsychiatric movement. People avoided psychiatrists. During the last years this situation has changed, but it is extremely difficult to change the attitude of people who have had such an experience for more than 50 years. We need decentralization of psychiatry, we need to get acquainted with foreign clinical schools. Our plans are to make psychiatry more human, more democratic, combine our efforts with the activities of social workers. 
THE POST-TOTALITARIAN CHALLENGE TO COMMUNITY PSYCHIATRY IN BULGARIA

TN Tomov

Department of Psychiatry, Higher Medical

Institute, Sofia 1431 , Bulgaria

Human systems (e.g. communities, institutions, families), aspiring to establish total control over the individual, bring forth oppressive settings, which leave behind devastating effects on mental Iife. The psychiatric institution in Bulgaria is permeated with values, norms and modes of operation which discourage autonomy and interfere with healthy functioning. In this it emulates the rigid patriarchal patterns of the culture.

The intrapsychic dynamics by way of which these destructive aspects of interpersonal relating get perpetuated should be acknowledged. For the process of change to advance unobstructed, it should be realized that the norms of the culture are incorporated as parts of the ego structure of the individuals raised in it, mental health workers included. It is through the structures in the mind and by way of defence mechanisms such as projection that authority and institutions acquire aspects such as harshness and punitiveness, that are so typical of the mental health settings in Bulgaria.

A shift from attempts to socially engineer the mental health care to efforts at selfexploration and gaining insights on the part of health workers have marked recent training programmes developed by the Bulgarian Psychiatric Association together with the New Bulgarian University. Little support and understanding of the critical importance of this development have been the typical response of Western sponsors.

MODELLING COMMUNITY CARE SYSTEM IN THE URBAN AREA J. Pfeiffer

Fokus, Association for the Mental Health Services, Dolákova 24, 18000 Praha-Bohnice, Czech Republic

1) A short statistic description of the present state of mental health services in the Czech Republic (CR)

2) The main community care systems in the $\mathrm{CP}$

3) The example of regional modelling community care system in urban area. Description of the process of modelling will be discussed in following items:

definition of target group

evaluation of therapeutical and social needs of clients

evaluation of resources

evaluation of sources

definition of the most effective interventions and activities completion of team, its training, lobbying local authorities setting of the project in region

evaluation of the efficacy of the project (6 months after its start), as regards economy, lowering of the revolving door syndrome, and satisfaction of clients and their families.

4) Results of community care efficacy in comparison with previous system. Exploiting of results for the transformation of the mental health care system at the national level.
COMMUNITY PSYCHIATRY IN POLAND - CURAENT DIFFICULTIES AND PERSPECTIVES

Elżbieta Nowik-Mroziewicz

Institute of Psychiatry and Neurology, Warsaw

Modem Community Psychiatry started to develop in the mid 70ties. Already then several centres were established. The centres were involved in variety of activities in local communities, preventive psychiatry and treatment. In 1989 thee were about 30 working centres, most of them were engaged mainly in treatment in home, individual and family therapy.

Current problems concerning Community Psychiatry stem from the past: lack of proper rules and regulation, which would support the development of this area, the biomedical concepts in thinking still maintained by many psychiatrist, insufficient information even between the centres etc. One has to take into account also economic difficulties of the last five years: closing down of same centres, reduction of staff, decreasing capacity of hostels, decreasing of number of jobs for patients, economical problems in many patients' families etc.

Nevertheless perspectives are promising. There is the 20 year old tradition, a number of well educated and trained therapeutists, much better understanding of the necessaries among psychiatrist and administration officials. Due to numerous foundations there are many possibilities to realise the different community programs (ex. for children, educationa programs for professionals and volunteers) outside the main stream of psychiatry. 